\title{
COMMENTARY
}

\section{How citrullination invaded rheumatoid arthritis research}

\author{
Walther J van Venrooij ${ }^{*}$ and Ger JM Pruijn
}

\begin{abstract}
Citrullination and the immune response to citrullinated proteins have been fundamental for the early recognition of rheumatoid arthritis by serological tests and a better understanding of its pathophysiology. In the first years after the initial publications, the focus was on the antibodies directed to citrullinated proteins. It is now realized that citrullinating enzymes and citrullinated proteins may have important roles in the maintenance of the inflammatory processes in the joints. There is also accumulating evidence for a direct role of citrullination in tissue destruction in the rheumatoid synovium. Here we will discuss the development and importance of anti-citrullinated protein antibodies in rheumatoid arthritis as well as recent findings implicating citrullination in the pathophysiology of rheumatoid arthritis.
\end{abstract}

The first indication that patients with rheumatoid arthritis (RA) produce antibodies to a specific autoantigen was published in 1964 by two Dutch scientists, Nienhuis and Mandema. The exact nature of this antigen, the so-called perinuclear factor, remained unclear for decades. In 1978, the target of seemingly unrelated RA-specific autoantibodies (that is, keratin) was identified. Almost 15 years later, Guy Serre's group convincingly showed that both antigens were identical to the cytokeratin filamentaggregating protein filaggrin (reviewed in [1]). Our own previously published results had shown that the newly made precursor of filaggrin in cultured buccal mucosa cells (that is, profilaggrin) did not react with RA antibodies [2]. This prompted us to consider the possibility that a post-translational modification of filaggrin, absent on newly made profilaggrin, was required for the formation of the antigenic target of these antibodies. Since 1994, we

\footnotetext{
* Correspondence: wvanvenrooij@yahoo.com

Department of Biomolecular Chemistry, Institute for Molecules and Materials and Nijmegen Centre for Molecular Life Sciences, Radboud University, PO Box 9101, NL-6500 HB, Nijmegen, The Netherlands
}

have tested several likely modifications using synthetic peptides. Indeed, citrullination, the enzymatic conversion of peptidylarginine into peptidylcitrulline, turned out to be essential to make peptides reactive with RA autoantibodies. We subsequently developed an enzyme-linked immunosorbent assay with citrullinated peptides and confirmed that the anti-peptidylcitrulline activity was specific for RA [3]. Our further work was directed to the development of the CCP2 test, using cyclic citrullinated peptides (CCPs) selected from random peptide libraries [4].

The discovery of $\mathrm{CCP} /$ protein as the most prominent RA-specific antigen had great impact on RA diagnostics and our understanding of RA pathophysiology. The following milestones can be noted (see [5] also).

1. After decades of intensive research by many groups, a specific diagnostic test for RA had finally been developed. The CCP2 test has a specificity of more than $95 \%$, is very sensitive ( $75 \%)$, and is still considered the gold standard in RA autoantibody testing. Since 2010, anti-citrullinated protein antibodies (ACPAs) have been included in the new American College of Rheumatology/European League Against Rheumatism classification criteria for RA.

2. Recently, an international reference preparation for ACPAs was evaluated by the International Committee for the Standardization of Autoantibodies in Rheumatic and Related Diseases [6]. It is available for the scientific community via the Centers for Disease Control and Prevention (Atlanta, GA, USA).

3. A positive CCP2 test predicts the development of RA, often years before clinical confirmation (reviewed in [5]). It appears that time to RA diagnosis is shorter in patients with high anti-CCP2 titers at enrollment as compared with those with low titers [7]. 
4. ACPA-positive RA is characterized by a more severe disease course. Early treatment of ACPA-positive individuals appears to be very effective.

5. ACPA-negative patients (about $25 \%$ of the total RA population) generally display a much milder course of disease. About 35\% of such ACPA-negative patients produce anti-carbamylated protein antibodies. Interestingly, the chemical product of carbamylation (that is, lysine converted to homocitrulline) is structurally very similar to citrulline [8].

6. Specific human leukocyte antigen (HLA) genes (DRB1 shared epitope (SE) alleles) not only are the most important genetic risk factor for RA but also are strongly associated with the production of ACPAs.

7. The best known environmental risk factor for RA, cigarette smoking, is a risk factor only for ACPApositive and not for ACPA-negative RA [9]. There is increasing evidence that smoking acts as a trigger for anti-citrulline immunity and does so mainly in the context of certain HLA genes and certain other genetic risk factors.

8. ACPAs and citrullinated antigens form immune complexes which stimulate the inflammatory process. Continuous production of such immune complexes ultimately results in the chronic inflammation, characteristic for RA (Figure 1).

\section{Topical aspects of citrullination in rheumatoid arthritis}

Autoimmunity against citrullinated autoantigens may be initiated at sites different from the joints. Indeed, evidence has been presented that citrullinated antigens may be produced in lungs during smoking or in gums during infection with bacteria like Porphyromonas gingivalis (reviewed in [10]; also, see Figure 1). Nevertheless, it has been shown that ACPAs accumulate in synovial fluid of active rheumatic joints as compared with the corresponding serum and that about $25 \%$ of synovial IgG-expressing $B$ cells are specific for citrullinated antigens in patients with ACPA-positive RA [11]. These data suggest that ACPAs at least partially are produced in the inflamed joints and that joint-specific citrullinated antigens may diversify and shape the ACPA profile.

Low-avidity ACPAs may be found in both healthy subjects and patients. However, using longitudinal samples obtained from individuals prior to disease onset, ACPA avidity was shown to increase over time until disease onset, after which no further avidity maturation was observed [12]. These data corroborate the notion that ACPAs play an important role in the pathogenesis of RA.

ACPAs represent a heterogeneous group of antibodies recognizing multiple citrullinated peptides and proteins. It remains to be established whether the subclassification

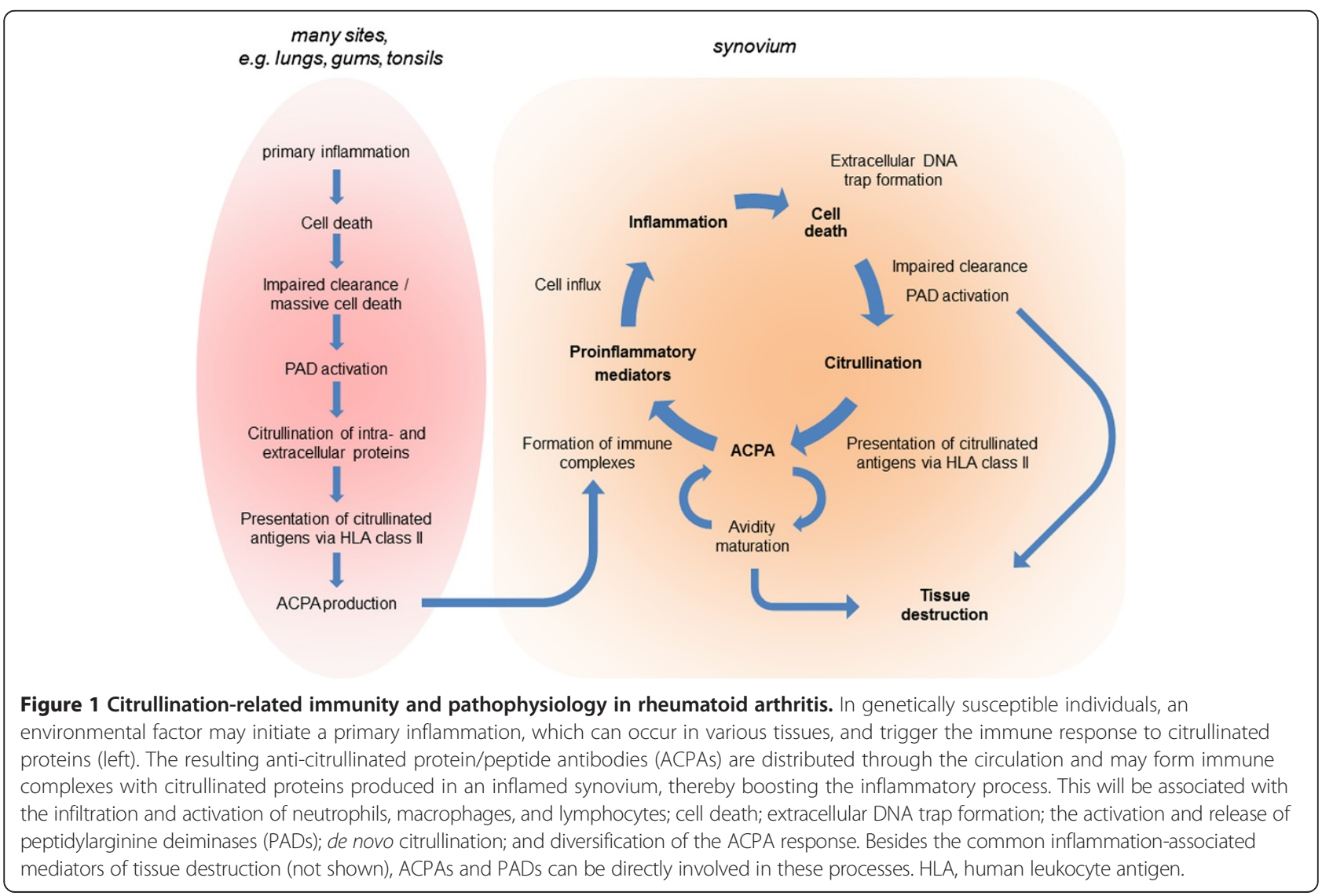




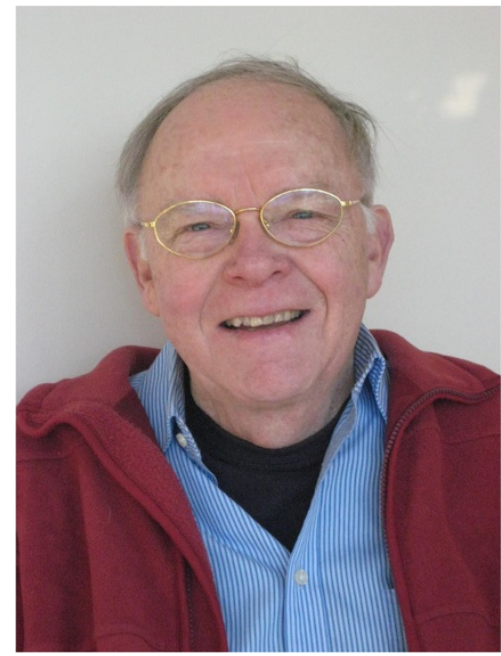

\section{Box 1 About Walther J van Venrooij and Ger JM Pruijn}

Walther J van Venrooij received his PhD in 1968 from the University of Utrecht (The Netherlands). After that he performed a postdoctoral research study at Harvard Medical School (Boston). In 1971, he became assistant professor in biochemistry at Radboud University in Nijmegen, The Netherlands, and in 1994 he was appointed full professor in biochemistry at the same university. His research activities focused primarily on the mechanisms active in autoimmunity. In particular, he studied autoimmune diseases like rheumatoid arthritis (RA), scleroderma, systemic lupus erythematosus, and myositis. His group was the first to publish that most patients with RA have antibodies directed to citrullinated antigens (1998). Subsequently they developed the CCP2 test to measure these antibodies, which are present very early in disease. This test allows earlier diagnosis and treatment of RA and has recently been added as a new serologic criterion for classifying this disease (2010). In 2002, he received the Carol Nachmann Award for his research on autoimmune diseases. In 2004, he received the Honorary Medal from the Netherlands Society for Rheumatology.

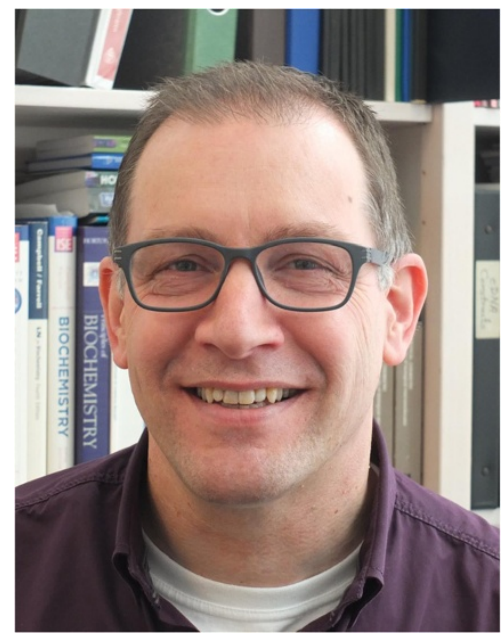

Ger JM Pruijn received his PhD in physiological chemistry from the University of Utrecht in 1989. His interest in autoimmunity developed during his studies as a postdoctoral researcher at the University of Nijmegen and grew after obtaining a fellowship from the Royal Netherlands Academy of Arts and Sciences. In 1997, he became assistant professor in biochemistry at the University of Nijmegen and became an associate professor at the same university in 2000. Since 2006, he has been professor in biomolecular chemistry and head of the Department of Biomolecular Chemistry of the Radboud University. His research is focused on autoantibody-autoantigen systems with a special interest in the role of post-translational modifications in the autoimmune response. 
based upon ACPA fine-specificity profiles is clinically meaningful.

In the last few years, it also became clear that citrullination may be instrumental to the tissue destruction processes in the synovium. ACPAs were shown to bind to osteoclast surfaces and to induce osteoclast differentiation and subsequent bone resorption [13]. This may explain why ACPA is strongly associated with bone erosion. It is tempting to speculate that the degradation of cartilage is mediated by similar mechanisms. Alternatively, this may be induced by citrullinating enzymes (peptidylarginine deiminases, or PADs), which may citrullinate proteins at the surface of cartilage, inducing their rapid degradation and destabilization of the cartilage.

Next to the antibodies, the citrullination of proteins in the synovium may lead to changes in important physiological processes. Citrullinated fibrinogen and citrullinated collagen type II are more immunogenic and arthritogenic in mouse models of arthritis, and citrullinated fibrinogen activates macrophages more than unmodified fibrinogen [10]. Recently, citrullination of fibronectin was shown to alter synovial fibroblast behavior [14]. Sokolove and colleagues [15] found that fragments of citrullinated proteins can bind to ACPAs and cause activation of macrophages and antigen-presenting cells. Ling and colleagues [16] showed that cell surface calreticulin interacts with the SE to transduce innate immune signals. Citrullination of calreticulin, an abundant process in inflamed synovial tissue, appeared to enhance its affinity for the SE, thus increasing its signaling potency significantly [16]. Interestingly, autocitrullination of PAD4 has been reported to inactivate this enzyme and to enhance its recognition by anti-PAD4 RA sera [17]. Although not all of these data have been confirmed yet by other groups, they strongly suggest that, in addition to ACPA production, protein citrullination can affect the pathophysiology of RA at several levels.

A very interesting phenomenon that links citrullination to inflammation and autoimmunity is the formation of extracellular DNA traps, which is part of the innate immune response [18]. Several inflammatory cells externalize a meshwork of chromatin fibers, containing citrullinated histones, decorated with granule-derived (antimicrobial) proteins. Extracellular trap formation is dependent on citrullination, and proteins associated with these traps may serve as self-antigens [19]. The potential relationship between the anti-citrullinated protein response in RA and citrullination in extracellular traps remains to be investigated.

It is evident by now that the study of citrullination, ACPAs, and citrullinating enzymes becomes more and more important to understand the pathophysiology of RA. It is likely that other modifications of cellular proteins may be intrinsic factors of other autoimmune diseases. Future studies have to prove this idea.
Note: This article is part of the collection Research through the eyes of pioneers. Other articles in this series can be found at http://arthritis-research.com/series/pioneers.

\section{Abbreviations}

ACPA: Anti-citrullinated protein/peptide antibody; CCP: Cyclic citrullinated peptide; HLA: Human leukocyte antigen; Ig: Immunoglobulin; PAD: Peptidylarginine deiminase; RA: Rheumatoid arthritis; SE: Shared epitope.

\section{Competing interests}

WJVV and GJMP are consultants to Axis-Shield Diagnostics Ltd (Dundee, Scotland) and Euro-Diagnostica AB (Malmö, Sweden).

Published: 29 Jan 2014

\section{References}

1. Simon M, Girbal E, Sebbag M, Gomes-Daudrix V, Vincent C, Salama G, Serre $\mathrm{G}$ : The cytokeratin filament-aggregating protein filaggrin is the target of the so-called "antikeratin antibodies," autoantibodies specific for rheumatoid arthritis. J Clin Invest 1993, 92:1387-1393.

2. Hoet RM, Boerbooms AM, Arends M, Ruiter DJ, van Venrooij WJ: Antiperinuclear factor, a marker autoantibody for rheumatoid arthritis: colocalisation of the perinuclear factor and profilaggrin. Ann Rheum Dis 1991, 50:611-618.

3. Schellekens GA, de Jong $B A$, van den Hoogen $F H$, van de Putte $L B$, van Venrooij WJ: Citrulline is an essential constituent of antigenic determinants recognized by rheumatoid arthritis-specific autoantibodies. J Clin Invest 1998, 101:273-281.

4. Schellekens GA, Visser $\mathrm{H}$, de Jong BA, van den Hoogen FH, Hazes JM, Breedveld FC, van Venrooij WJ: The diagnostic properties of rheumatoid arthritis antibodies recognizing a cyclic citrullinated peptide. Arthritis Rheum 2000, 43:155-163.

5. van Venrooij WJ, van Beers JJ, Pruijn GJ: Anti-CCP antibodies: the past, the present and the future. Nat Rev Rheumatol 2011, 7:391-398,

6. Bizzaro N, Pregnolato F, van Boekel MA, Villalta D, Tozzoli $R$, Tonutti E, Antico A, Borghi MO, Wiik A, Meroni PL: Preliminary evaluation of the first international reference preparation for anticitrullinated peptide antibodies. Ann Rheum Dis 2012, 71:1388-1392.

7. Bizzaro N, Bartoloni E, Morozzi G, Manganelli S, Riccieri V, Sabatini P, Filippini M, Tampoia M, Afeltra A, Sebastiani G, Alpini C, Bini V, Bistoni O, Alunno A, Gerli R, the Forum Interdisciplinare per la Ricerca nelle Malattie Autoimmuni (FIRMA Group): Anti-cyclic citrullinated peptide antibody titer predicts time to rheumatoid arthritis onset in patients with undifferentiated arthritis: results from a 2-year prospective study. Arthritis Res Ther 2013, 15:R16.

8. Shi J, Knevel R, Suwannalai P, van der Linden MP, Janssen GM, van Veelen PA, Levarht NE, van der Helm-van Mil AH, Cerami A, Huizinga TW, Toes RE, Trouw LA: Autoantibodies recognizing carbamylated proteins are present in sera of patients with rheumatoid arthritis and predict joint damage. Proc Natl Acad Sci U S A 2011, 108:17372-17377.

9. Klareskog L, Malmstrom V, Lundberg K, Padyukov L, Alfredsson L: Smoking, citrullination and genetic variability in the immunopathogenesis of rheumatoid arthritis. Sem Immunol 2011, 23:92-98.

10. Quirke AM, Fisher BA, Kinloch AJ, Venables PJ: Citrullination of autoantigens: upstream of TNFalpha in the pathogenesis of rheumatoid arthritis. FEBS Lett 2011, 585:3681-3688.

11. Amara K, Steen J, Murray F, Morbach H, Fernandez-Rodriguez BM, Joshua V, Engström M, Snir O, Israelsson L, Catrina Al, Wardemann H, Corti D, Meffre E, Klareskog L, Malmström V: Monoclonal IgG antibodies generated from joint-derived $B$ cells of RA patients have a strong bias toward citrullinated autoantigen recognition. J Exp Med 2013, 210:445-455.

12. Suwannalai $P$, van de Stadt LA, Radner $H$, Steiner G, El-Gabalawy HS, Zijde $C M$, van Tol MJ, van Schaardenburg D, Huizinga TW, Toes RE, Trouw LA: Avidity maturation of anti-citrullinated protein antibodies in rheumatoid arthritis. Arthritis Rheum 2012, 64:1323-1328. 
13. Harre U, Georgess D, Bang H, Bozec A, Axmann R, Ossipova E, Jakobsson PJ, Baum W, Nimmerjahn F, Szarka E, Sarmay G, Krumbholz G, Neumann E, Toes R, Scherer HU, Catrina Al, Klareskog L, Jurdic P, Schett G: Induction of osteoclastogenesis and bone loss by human autoantibodies against citrullinated vimentin. J Clin Invest 2012, 122:1791-1802.

14. Shelef MA, Bennin DA, Mosher DF, Huttenlocher A: Citrullination of fibronectin modulates synovial fibroblast behavior. Arthritis Res Ther 2012, 14:R240.

15. Sokolove J, Zhao X, Chandra PE, Robinson WH: Immune complexes containing citrullinated fibrinogen costimulate macrophages via Toll-like receptor 4 and Fcgamma receptor. Arthritis Rheum 2011, 63:53-62.

16. Ling S, Cline EN, Haug TS, Fox DA, Holoshitz J: Citrullinated calreticulin potentiates rheumatoid arthritis shared epitope signaling. Arthritis Rheum 2013, 65:618-626.

17. Andrade F, Darrah E, Gucek M, Cole RN, Rosen A, Zhu X:

Autocitrullination of human peptidyl arginine deiminase type 4 regulates protein citrullination during cell activation. Arthritis Rheum 2010, 62:1630-1640

18. Simon D, Simon HU, Yousefi S: Extracellular DNA traps in allergic, infectious, and autoimmune diseases. Allergy 2013, 68:409-416.

19. Knight JS, Carmona-Rivera C, Kaplan MJ: Proteins derived from neutrophil extracellular traps may serve as self-antigens and mediate organ damage in autoimmune diseases. Front Immunol 2012, 3:380.

$10.1186 / a r 4458$

Cite this article as: van Venrooij and Pruijn: How citrullination invaded rheumatoid arthritis research. Arthritis Research \& Therapy 2014, 16:103 